\title{
KOLANGITIS AKUT PADA PENDERITA TUMOR KLATSKIN
}

\author{
Muhamad Ayus Astoni1,2, Syadra Bardiman³, Mitayani Purwoko ${ }^{4}$ \\ ${ }^{1}$ Dokter Pendidik Klinik Fakultas Kedokteran Universitas Muhammadiyah Palembang \\ 2Staf Departemen Ilmu Penyakit Dalam RSUD Palembang BARI \\ 3Departemen Ilmu Penyakit Dalam RS MoechamadHoesin Palembang \\ ${ }^{4}$ Staf Departemen Biologi Kedokteran Fakultas Kedokteran Universitas Muhammadiyah Palembang
}

\begin{abstract}
ABSTRAK
Tumor Klatskin merupakan suatu kolangiokarsinoma tipe ekstrahepatik yang bersifat ganas dan timbul dari epitel duktus koledokus dan kedua percabangannya. Seorang wanita usia 47 tahun mengalami keluhan badan panas sejak 1 hari sebelum masuk rumah sakit. Satu hari sebelum masuk rumah sakit, pasien mengalami demam tinggi terus- menerus, tidak disertai dengan menggigil. Keluhan disertai nyeri hebat di perut kanan atas sampai ke ulu hati, nafsu makan menurun, mual setiap hendak makan, BAK berwarna seperti teh, BAB biasa, dan mata terlihat kuning. Satu minggu sebelum masuk rumah sakit, keluhan nyeri perut makin sering timbul disertai demam, mual, kadang-kadang muntah bila makan, dan nafsu makan makin turun. Hasil MRI menunjukkan kesan lesi hipointens dengan tepi yang irreguler di distal CBD sepanjang $\pm 2 \mathrm{~cm}$ dengan dilatasi sedang CBD di bagian proksimalnya dan dilatasi ringan IHBD serta tak tampak dilatasi pada duktus pankreatikus, mengesankan massa di distal CBD yang menyebabkan obstruksi, curiga Klatskin Tumor Type 1 (berdasarkan Bismuth Classification). Pasien menolak dilakukan tindakan pembedahan maupun kemoterapi. Pasien mengaku merasa dalam kondisi baik, keluhan nyeri perut sangat jarang, nafsu makan sudah meningkat.
\end{abstract}

Kata kunci: kolangitis akut, TumorKlatskin, kolangitis

\section{ABSTRACT}

Klatskin tumor is an malignant extrahepatic type of cholangiocarcinoma and arises from the choledocus ducte pithelium and its two branches. A 47-year-old woman has afever since one day before being hospitalized. One day before being admitted to the hospital, the patient experienced a persistent high fever, not accompanied by shivering. Complaints accompanied by severe pain in the right upper abdomen to the epigastrium, decreasedappetite, nausea, urine coloredliketea, normal bowelmovements, and eyes look yellow. One week before being hospitalized, complaintsof abdominal pain often came with fever, nausea, sometimes vomiting when eating, and appetite decreased. The MRI results showed hypointense lesions with irregular edges in the distal $\mathrm{CBD}$ of $\pm 2 \mathrm{~cm}$ with moderate $\mathrm{CBD}$ dilatation in the proximal part and mild IHBD dilatation and no visible dilatation of the pancreatic ducts, impressive distal CBD mass causing obstruction, suspicious of Klatskin Tumor Type 1 (basedonBismuthClassification). Patient refused surgeryor chemotherapy. Patient claimed to feel in good condition, complaints of abdominal pain was veryrare, appetite has increased.

Keywords: acutecholangitis, Klatskin tumor, cholangitis

\section{PENDAHULUAN}

Kolangiokarsinoma adalah suatu keganasan dari sistem duktus biliaris yang berasal dari hati dan berakhir pada ampullavateri. Keganasan ini dapat terjadi sepanjang sistem saluran biliaris, baik intrahepatik maupun ekstrahepatik .Percabangan saluran empedu adalah tempat yang paling sering terkena, 60-80\% dari kolangiokarsinoma terjadi di daerah percabangan saluran empedu. Semua kolangiokarsinoma pertumbuhannya lambat, infiltratif lokal, dan metastasenya lambat. ${ }^{1-3}$ Tumor Klatskin merupakan suatu Kolangiokarsinoma tipe ekstrahepatik. Tumor ini 
merupakan tumor yang terdapat pada sistem duktus biliaris. Dr. G. Klastkin mendeskripsikan mengenai tumor ini pertama kali pada tahun 1965 dan menemukannya dalam 13 kasus. Di AS setiap tahun tercatat 2.500 kasus penyakit tumor Klatskindari 5.000 kasus kanker kandung empedu. Prevalensi tertinggi terdapat di kalangan orang Asia (10 kali lebih banyak) yang diakibatkan oleh infeksi parasit kronik endemik. ${ }^{4}$

Etiologi kolangiokarsinomabelum jelas sepenuhnya. Sejumlah kondisi patologisyang menyebabkan epitel saluran empedu cedera baik akut atau kronis dapat menyebabkan saluran empedu tersebut rentan terhadap perubahan kearah keganasan. Primarysclerosingcholangitis(PSC), suatu kondisi peradangan idiopatik dari saluran bilier utama, merupakan salah satu faktor risiko utama perkembangan kolangiokarsinomapada sekitar 40\% dari penderita kanker ini. Prevalensi kolangiokarsinoma pada panderita PSC sekitar $5 \%-15 \%$, dengan insiden rate setiap tahun sekitar 0,6\%-1,5\%. Faktor-faktor risiko lainnya yang sudah teridentifikasi berkaitan dengan keganasan ini antara lain : Penyakit kistik kongenital kandung empedu, seperti kistakoledokus atau penyakit Caroli;infeksi parasit saluran empedu kronisoleh Clonorchissinensis dan Opisthorchisviverrini, hepatolithiasis dan choledocholithiasis, paparan terhadap asbes dan nitrosamin, dan penggunaan zat kontras radiologi.5-8

$$
\text { Pada kebanyakan kasus, }
$$

kolangiokarsinoma tidak menunjukkan gejala klinis yang nyata, dan gejala klinis baru muncul bila penyakit sudah pada stadium lanjut. Gejala utama dari tumor klatskin adalah ikterus,disertai keluhan yang tidak spesifik, seperti penurunan berat badan dan nyeri perut di daerah kanan atas dan epigastrium.Kolangitisakut merupakan komplikasi yang biasa terjadi pada penderita kolangiokarsinoma. ${ }^{9,10}$

Diagnosis histolopatologispra operasi tumor Klatskin sangat sulit didapatkan,meskipun telah dilakukan biopsi perkutan dan brushings untuk sitologi. Secara umum, diagnosis histopatologi tidak diperlukan sampai dilakukan intervensi bedah. Namun, diagnosis histopatologi sangat penting untuk membedakan antara akibat kolangitissklerosis primer (PSC) dengan striktur akibat tumor Klatskin. ${ }^{11,12}$

Terapi

kuratif

untukkolangiokarsinomahanya reseksi bedah atau transplantasi hati, tetapi sebagian besar pasien terdiagnosis pada stadium lanjut, ketika terapi bedah sudah tidak memungkinkan lagi. Hal ini harus menjadi perhatian untuk dilakukannya deteksi dini terjadinya kolangiokarsinoma, dan salah satu faktor risiko penting timbulnya adalah primer sclerosingcholangitis (PSC). Tanpa intervensi bedah, kematian akibat penyakit sangat tinggi. ${ }^{13-15}$

\section{LAPORAN KASUS}

Seorang wanita usia 47 tahun mengalami keluhan badan panas sejak 1 hari sebelum masuk rumah sakit. Satu hari sebelum masuk rumah sakit, pasien mengalami demam tinggi terus- menerus, tidak disertai dengan menggigil. Keluhan disertai nyeri hebat di perut kanan atas sampai ke ulu hati, nafsu makan menurun, mual setiap hendak makan, BAK 
bewarna seperti teh, $\mathrm{BAB}$ biasa, dan mata terlihat kuning. Satu minggu sebelum masuk rumah sakit, keluhan nyeri perut makin sering timbul disertai demam, mual, kadang-kadang muntah bila makan, dan nafsu makan makin turun.

Sejak sekitar 1 bulan sebelum masuk rumah sakit, pasien sering mengeluh nyeri pada perut bagian kanan atas yang hilang timbul, disertai mual,nafsu makan mulai menurun, kadang-kadang badan terasa meriang. Pasien tidak pernah memiliki riwayat mengonsumsi jamu, obat penghilang nyeri, dan minum alkohol. Keluhan ini baru pertama kali dirasakan.

Pemeriksaan fisik menemukan keadaan umum sakit berat, kesadaran compos mentis dengan tanda vital tekanan darah 150/80 $\mathrm{mmHg}$, denyut nadi $102 \mathrm{kali} / \mathrm{menit}$ reguler, temperatur tubuh $39,6^{\circ} \mathrm{C}$, pernapasan 20 kali/menit. Abnormalitas ditemukan pada pemeriksaan fisik abdomen dimana pada inspeksi tampak perut membesar ke samping, namun tidak disertai venektasi, caputmedusae, ikterik, hiperpigmentasi, dan penonjolan umbilikus. Hasil palpasi dan auskultasi menunjukkan semua dalam batas normal, namun pada perkusi terdengar shiftingdullness. Pada pemeriksaan ekstremitas tampak kulit ekstremitas atas dan bawah ikterik.

Pemeriksaan darah di laboratorium dilakukan pada saat pasien masuk rumah sakit. Hasil laboratorium diperoleh data padaTabel 1. Sementara, hasil USG abdomen dirangkum dalam tabel 2 dan hasil MRI abdomen dirangkum dalam tabel 3.

Tabel 1. Hasil pemeriksaan laboratorium

\begin{tabular}{lc}
\hline Jenis Pemeriksaan & Hasil \\
\hline Hemoglobin & $9,6 \mathrm{~g} / \mathrm{dL}$ \\
Leukosit & $16.400 / \mathrm{ul}$ \\
Trombosit & 812.000 \\
Hematokrit & $29,0 \%$ \\
Differentialcount & $0,0 / 0,0 / 95,4 / 3,3 / 1,3$ \\
SGOT & $843 \mathrm{U} / \mathrm{L}$ \\
SGPT & $288 \mathrm{U} / \mathrm{L}$ \\
Bilirubin total & $3,34 \mathrm{mg} / \mathrm{dl}$ \\
Bilirubin Direk & $3,33 \mathrm{mg} / \mathrm{d} /$ \\
Bilirubin Indirek & $0,01 \mathrm{mg} / \mathrm{dl}$ \\
Gula darah sewaktu & $93 \mathrm{mg} / \mathrm{dl}$ \\
Kreatinin & $1,01 \mathrm{mg} / \mathrm{dl}$ \\
eGFR & $59,009 \mathrm{ml} / \mathrm{min} / 1,73 \mathrm{~m}^{2}$ \\
Ureum & $23,70 \mathrm{mg} / \mathrm{dl}$ \\
Asam urat & $2,6 \mathrm{mg} / \mathrm{dl}$ \\
HBsAg Kualitatif & Non reaktif \\
Anti HCV Rapid & Non Reaktif \\
Fosfatase alkali & $878 \mathrm{U} / \mathrm{L}$ \\
Gamma GT & $945 \mathrm{U} / \mathrm{L}$ \\
Dengue NS1 Rapid & Negatif \\
\hline
\end{tabular}

Vol. 1 No.5 Agustus 2018 


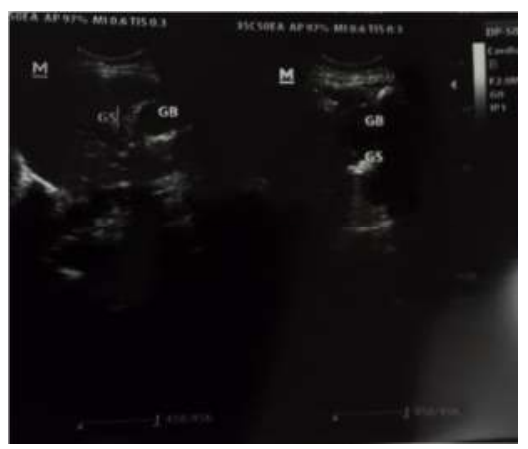

Gambar 1. Hasil USG abdomen

Tabel 2. Hasil pemeriksaan USG abdomen

\begin{tabular}{|c|c|c|}
\hline Organ & USG abdomen hari kelima & USG abdomen hari keenam \\
\hline Hepar & $\begin{array}{l}\text { Ukuran normal, tepi tajam, permukaan } \\
\text { rata, intensitas ekoparenkim homogen } \\
\text { halus. Sistem portal dan vaskular tidak } \\
\text { melebar. Tampak asites minimal di } \\
\text { perigallbladder dan perilienalis. }\end{array}$ & $\begin{array}{l}\text { Ukuran mengecil, tepi ireguler, } \\
\text { intensitas ekoparenkim heterogen } \\
\text { kasar. Sistem portal dan vaskular } \\
\text { tidak melebar. Tampak asites } \\
\text { minimal di perigallbladder dan } \\
\text { perilienalis. Tampak efusi pleura } \\
\text { minimal. }\end{array}$ \\
\hline $\begin{array}{l}\text { Kar } \\
\text { em }\end{array}$ & $\begin{array}{l}\text { Bentuk dan ukuran normal, dinding } \\
\text { tampak edema. Tidak tampak } \\
\text { batu/sludge. CBD melebar, tampak } \\
\text { massa di distal CBD. tampak pelebaran } \\
\text { IHBD. }\end{array}$ & $\begin{array}{l}\text { Bentuk dan ukuran normal, dinding } \\
\text { tampak edema. Tidak tampak } \\
\text { batu/sludge. }\end{array}$ \\
\hline Lien & $\begin{array}{l}\text { Bentuk dan ukuran normal, intensitas } \\
\text { ekoparenkim homogen, tidak tampak } \\
\text { massa/SOL (-) }\end{array}$ & $\begin{array}{l}\text { Bentuk dan ukuran normal, } \\
\text { intensitas ekoparenkim homogen, } \\
\text { tidak tampak massa/SOL }(-)\end{array}$ \\
\hline Pankreas & $\begin{array}{l}\text { Bentuk dan ukuran normal, intensitas } \\
\text { ekoparenkim homogen, tidak tampak } \\
\text { massa/SOL (-). duktus pankreatikus } \\
\text { tidak melebar. }\end{array}$ & $\begin{array}{l}\text { Bentuk dan ukuran normal, } \\
\text { intensitas ekoparenkim homogen, } \\
\text { tidak tampak massa/SOL (-), } \\
\text { duktus pankreatikus tidak melebar. }\end{array}$ \\
\hline Vesicaurinaria & SEHADANG & Normal \\
\hline $\begin{array}{l}\text { Aorta } \\
\text { abdominalis }\end{array}$ & $\begin{array}{l}\text { Tidak tampak pembesaran KGB para } \\
\text { aorta. }\end{array}$ & $\begin{array}{l}\text { Tidak tampak pembesaran KGB } \\
\text { para aorta. }\end{array}$ \\
\hline Kesan & $\begin{array}{l}\text { Obstruksi saluran empedu intra hepatik, } \\
\text { curiga massa di distal CBD. }\end{array}$ & $\begin{array}{l}\text { CirrhosisHepatis disertai hipertensi } \\
\text { portal. Tidak tampak transformasi } \\
\text { kearahmalignansi. }\end{array}$ \\
\hline
\end{tabular}


Tabel 3. Hasil pemeriksaan MRI abdomen

\begin{tabular}{|c|c|}
\hline Organ & $\begin{array}{l}\text { MRI abdomen hari } \\
\text { kesembilan }\end{array}$ \\
\hline Hepar & $\begin{array}{l}\text { Besar dan bentuk normal, tepi } \\
\text { rata, struktur parenkimnya } \\
\text { homogen, tidak tampak SOL. } \\
\text { Tidak tampak dilatasi duktus } \\
\text { bilier intra dan ekstrahepatik. } \\
\text { Struktur vaskuler tampak } \\
\text { normal. }\end{array}$ \\
\hline Kandung empedu & $\begin{array}{l}\text { Tidak membesar, bentuk } \\
\text { normal, dinding normal. Tidak } \\
\text { tampak batu di dalamnya. } \\
\text { Ductus cysticus tidak melebar. }\end{array}$ \\
\hline Lien & $\begin{array}{l}\text { Tidak membesar, tepi rata. } \\
\text { Tidak tampak lesi fokal. }\end{array}$ \\
\hline Pankreas & $\begin{array}{l}\text { Besar dan bentuknya normal } \\
\text { Tidak tampak SOL, area } \\
\text { nekrotik maupun pseudocyst } \\
\text { Duktus pankreatikus tidak } \\
\text { melebar. }\end{array}$ \\
\hline Aorta abdominalis & $\begin{array}{l}\text { Bentuk dan kalibernya baik. } \\
\text { Tidak tampak pembesaran } \\
\text { kelenjar getah bening } \\
\text { paraaorta. }\end{array}$ \\
\hline Ductuscholedochus & $\begin{array}{l}\text { Tampak dilatasi sedang, tampak lesi } \\
\text { hipointens dengan tepi irreguler } \\
\text { sepanjang } \pm 2 \mathrm{~cm} \text { di distal CBD. }\end{array}$ \\
\hline $\begin{array}{l}\text { Duktus bilier } \\
\text { intrahepatik dan } \\
\text { duktus bilier } \\
\text { hepatikus }\end{array}$ & Tampak dilatasi ringan. \\
\hline Ductus pancreaticus & Tidak tampak dilatasi dan batu. \\
\hline Kandung empedu & $\begin{array}{l}\text { Tidak membesar, bemtuknya normal, } \\
\text { tidak tampak batu didalamnya, } \\
\text { dinding rata, tidak tampak SOL, } \\
\text { duktus cystikus tidak melebar. }\end{array}$ \\
\hline Kesan & $\begin{array}{l}\text { Lesi hipointens dengan tepi yang irreguler di distal CBD sepanjang } \pm \\
2 \mathrm{~cm} \text { dengan dilatasi sedang CBD di bagian proksimalnya dan dilatasi } \\
\text { ringan IHBD serta tak tampak dilatasi pada duktus pankreatikus, } \\
\text { mengesankan massa di distal CBD yang menyebabkan obstruksi, } \\
\text { curiga Klatskin Tumor Type } 1 \text { (berdasarkan Bismuth Classification) }\end{array}$ \\
\hline
\end{tabular}




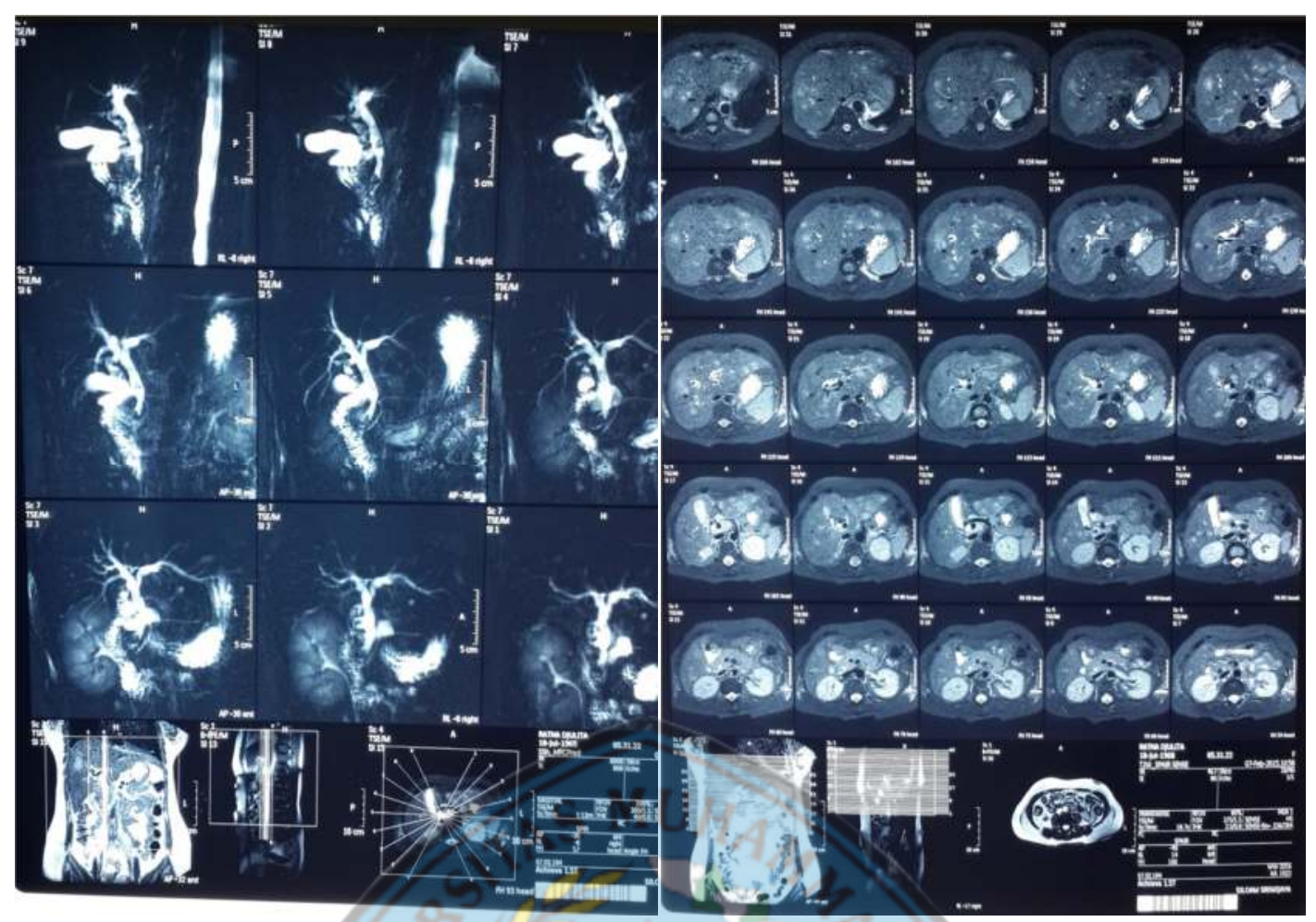

Gambar 2. Hasil MRI abdomen

Pada hari keenam dilakukan pemeriksaan Ca 19-

9 dan diperoleh hasil kadar Ca 19-9 pasien sebesar 34.443,62 /ml. Pasien kemudian didiagnosis dengan Kolangitis Akut etcausa Obstruksi duktus choledochus distal etcausa Tumor Klatskin dan ditatalaksana dengan diet hati II, IVFD Aseringgtt XX/ menit makro, Ciprofloksasin 2 × $500 \mathrm{mg}$, Ondansetron 3 × 8 mg iv, Ranitidin 2 x 300 mg iv, Sistenol 3 x 500 mg, dan Livercare 3 x 1 tablet. Prognosis quoadvitam dan quoadfunctionam dinyatakan tidak baik.

\section{PEMBAHASAN}

Pada kolangitis akut umumnya terjadi obstruksi saluran empedu, sehingga pengobatan definitif hanya dapat dicapai dengan menghilangkan obstruksi saluran empedu dan pengobatan terhadap infeksi. Hal ini dapat dicapai dengan tindakan operasi, drainase perkutan (PTBD) atau dengan endoskopi (yaitu, dengan ERCP).

Pemberian antibiotik ditujukan terhadap bakteri-bakteri enterik, sehingga antibiotik yang diberikan pada kolangitis akut harus merupakan kombinasi penghambat $\beta$ laktam dengan ampisilin atau sulbaktam, atau piperasilin. pilihan lainnya adalah sefalosporin generasi ketiga atau generasi keempat meskipun aktivitasnya terhadap enterokokus kurang dibandingkan dengan Antibiotik kombinasi penghambat $\beta$-laktam dengan ampisilin / sulbaktam. ${ }^{16-21}$

Kolangitis akut merupakan penyakit dengan angka kematian yang cukup tinggi, sehingga harus segera diterapi dengan antibiotik dan terapi-terapi penunjang lainnya termasuk dekompresi / drainase sistem bilier untuk kasus-kasus yang tidak menunjukkan respon dengan terapi konservatif. Drainase 
saluran empedu dapat dilakukan melalui pembedahan, ERCP, atau perkutan (PTBD). Tindakan ERCP dapat menggantikan prosedur bedah terbuka pada penatalaksanaaankolangitis akut dan berhasil pada lebih dari 90\% kasus. ERCP umumnya memiliki tingkat morbiditas lebih rendah daripada operasi terbuka, dan lebih mungkin digunakan untuk pengobatan definitif (misalnya, dengan pengambilan batu di saluran empedu ) dibandingkan dengan drainase empedu perkutan (PTBD). ${ }^{16-18,20,23}$

Pada kasus ini, pasien sudah diterapi dengan antibiotik golongan sefalosforin generasi III, tidak dilakukan drainase saluran empedu oleh karena menunjukkan respon dengan terapi konservatif.

Tidak ada terapi medis yang efektif untuk tumor Klatskin, bahkan dengan reseksi bedah lengkap, masih sering terjadi kekambuhan. Kelangsungan hidup rata-rata setelah dilakukan reseksi tumor adalah 9-12 bulan, dan kelangsungan hidup lima tahun $22 \%$ 44\%. ${ }^{3,4}$ Sebelum dilakukan tindakan reseksi tumor, harus dilakukan penentuan stadium tumor yang akurat. Protokol penatalaksanaan terbaru menganjurkan dilakukan transplantasi hati, dan sebelum transplantasi, dilakukan laparotomi eksploratif untuk staging ulang. Untuk sebagian besar pasien tumor Klatskin yang tidak bisa lagi dilakukan reseksi bedah atau transplantasi, dapat dilakukan terapi photodynamic (PDT), dan radioterapi (Eksternal, intraluminal, atau brachytherapy). $3,9,10$

Kemoterapi yang dapat digunakan untuk tumor Klatskin adalah : 5-FU, methanesulfon-m-anisidide, cisplatin, rifampisin, mitomycin C, paclitaxel, dan gemcitabine, dengan parsial Respon $0 \% \quad-9 \%$ dan kelangsungan hidup rata-rata 2-12 bulan. Kemoterapi kombinasi, yang banyak digunakan pada tumor Klatskin adalah ECF (epirubicin + cisplatin + 5-FU), tetapi dengan hasil yang mengecewakan. Meskipun belum didukung dengan data-data yang lengkap, pada beberapa penelitian yang dilakukan, menunjukkan peningkatan harapan hidup yang signifikan pada penderita klatskin tumor yang menjalani reseksi bedah dan adjuvant radio-kemoterapi. 9,10,12-15

4. Pada kasus ini, pasien menolak dilakukan tindakan pembedahan maupun kemoterapi dengan alasan merasa sudah membaik dengan pengobatan yang diberikan selama perawatan di rumah sakit dan takut dengan efek samping pembedahan dan radiokemoterapi. Pada saat kontak terakhir, pasien mengaku merasa dalam kondisi baik, keluhan nyeri perut sangat jarang, nafsu makan sudah meningkat, dan saat ini meneruskan pengobatan paliatif sendiri dengan obat yang diberikan saat keluar dari rumah sakit yaitu Livercare 2 x 1 tablet. Pasien mengaku jiika merasa nyeri perut maka pasien obati sendiri dengan Spasmonen 1 tablet dan Pantozol 1 capsul.

\section{SIMPULAN}

Tumor Klatskinadalah tumor ganas yang timbul dari epitel duktus koledokus dan kedua percabangannya dengan prognosis yang buruk, yang timbul dari transformasi maligna sel-sel epitel yang melapisi saluran bilier. Kelangsungan hidup rata-rata kurang dari 24 
bulan dan respon terhadap kemoterapi sangat kecil.

\section{DAFTAR PUSTAKA}

1. deGroen PC, Gores GJ, LaRusso NF, etal.Biliarytractcancers. N EnglJMed 1999;341: 1368-78.

2. Hirohashi K, Venishi T, Kubo S, etal.Macroscopictypesofintrahepaticcholang iocarcinoma:

clinicopathologicfeaturesandsurgicaloutcom es. Hepatogastroenterology 2002;49: 326-9.

3. Olnes MJ, Erlich R. A reviewandupdateoncholangiocarcinoma. Oncology 2004;66: 167-79.

4. Alejandro Serrablo, Luis Tejedor. Outcomeofsurgicalresection (1) in Klatskintumors. World J GastrointestOncol2013 July 15; 5(7): 147-158.

5. Burak K, Angulo P, Pasha TM, Egan K, Petz J, Lindor KD. Incidenceandriskfactorsforcholangiocarcin oma in primarysclerosingcholangitis. Am J Gastroenterol2004; 99: 523-526.

6. Angulo P, Lindor Primarysclerosingcholangitis. Hepatology1999; 30: 325-332.

7. Boberg KM, Bergquist A, Mitchell S, Pares A, Rosina F, Broomé U, Chapman R, Fausa O, Egeland T, Rocca G, Schrumpf E. Cholangiocarcinoma in primarysclerosingcholangitis: riskfactorsandclinicalpresentation. Scand J Gastroenterol2002; 37: 1205-1211.

8. Bergquist A, Ekbom A, Olsson R, Kornfeldt D, Lööf L, Danielsson A, Hultcrantz R, Lindgren S, Prytz H, Sandberg-Gertzén H, Almer S, Granath F, Broomé U. Hepaticandextrahepaticmalignancies in primarysclerosingcholangitis. J Hepatol2002; 36: 321-327.
9. Mert A, Ozaras R, Tabak F, Ozturk R, Bilir M. Tumor Klatskin. Eur J Intern Med 2003;14:511.

10. Khan SA, etal.Guidelinesforthe diagnosis andtreatmentofcholangiocarcinoma: consensusdocument. Gut 2002;51(Suppl 6):VI1-9.

11. Nehls O, Gregor M, Klump B. Serum andbilemarkersforcholangiocarcinoma. SeminLiver Dis 2004; 24: 139-154.

12. Alvaro D, Macarri G, Mancino MG, Marzioni M, Bragazzi M, Onori P, Corradini SG, Invernizzi P, Franchitto A, Attili AF, Gaudio E, Benedetti A. Serum andbiliary insulin-likegrowthfactor I andvascularendothelialgrowthfactor in determiningthecauseofobstructivecholestasi s. Ann Intern Med2007; 147: 451-459.

13. Nagorney DM, Kendrick ML. Hepaticresection in thetreatmentofhilarcholangiocarcinoma. AdvSurg 2006;40:159-71.

14. Patel T. Cholangiocarcinoma. NatClinPractGastroenterolHepatol 2006;3:33-42.

15. Jarnagin WR, Shoup M. Surgicalmanagementofcholangiocarcinoma. SeminLiver Dis 2004;24:189-99.

16. Zhang W.Z., Chen Y.S., Wang J.W, etal. Early diagnosis andtreatmentofsevereacutecholangitis. World J Gastroenterol (2002); 8(1):150-152.

17. Malet P.F. AcuteBacterialCholangitis, In Kaplowitz N, Ed. LiverandBiliaryDiseases. 2 nd Ed, Williams andWilkins, Baltimore. (1996) : 685-687.

18. Sartelli M., Cristian Tranà C. A focusonacutecholecystitisandacutecholangit is. JournalofAcuteDisease (2012): 77-81.

19. Qin Y.S., Li Q.Y., Yang F.C. Riskfactorsandincidenceofacutepyogenicch olangitis. HepatobiliaryPancreat Dis Int, (2012): 11(6): 650-54. 
20. Beuers U. BiiaryInfection, in Dancygier H, Ed. ClinicalHepatology.Springer-Verlag Berlin Heidelberg (2010): 1493-1502.

21. Basoli A, Schietroma M, DeSantis A, etal.Acutecholangitis:

diagnosticandtherapeuticproblems. Italian J SurgSci (1996) : 16:261-267.

22. Kiriyama S, Takada T, Strasberg SM, Solomkin JS, Mayumi T, Pitt HA, etal. New diagnosticcriteriaandseverityassessmentofac utecholangitis in revised Tokyo Guidelines. J HepatobiliaryPancreatSci. 2012;19:54856.

23. Tsuyuguchi T, Sugiyama H, Sakai Y, Nishikawa T, Yokosuka O, Mayumi T, etal.Prognosticfactorsofacutecholangitis in casesmanagedusingthe Tokyo Guidelines. J HepatobiliaryPancreatSurg. $\quad$ 2012;19:55765. 